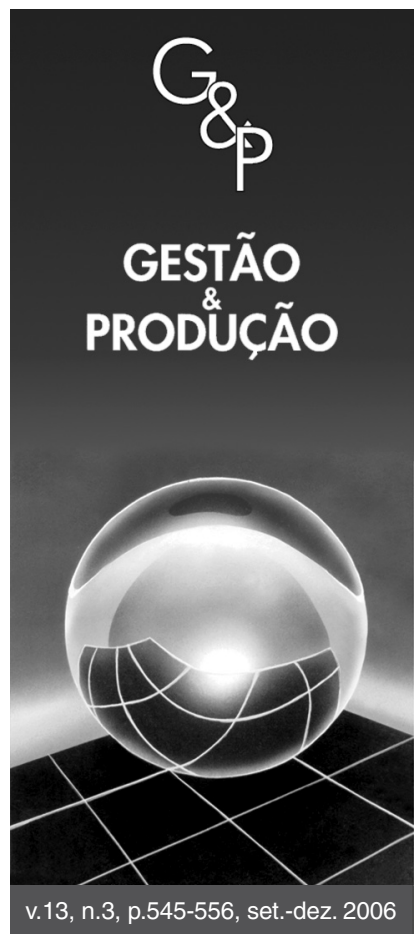

\title{
PRÁTICAS DE GESTÃO DE RESÍDUOS DA CONSTRUÇÃO CIVIL: UMA ANÁLISE DA INCLUSÃO SOCIAL DE CARROCEIROS E CIDADÃOS DESEMPREGADOS
}

Paulo José Silva

Rua Barbosa Lima, 829, apto. 403, bloco 1, Centro, Universidade Federal de Lavras - UFLA, CEP 37200-000, Lavras, MG, Brasil, e-mail: paulojoses@uol.com.br

Mozar José de Brito Campus Universitário, Universidade Federal de Lavras, C. P. 37, CEP 37200-000 - Lavras, MG, Brasil, e-mail: mozarjdb@ufla.br

Recebido em 01/6/2006 Aceito em 25/10/2006

Resumo

Este artigo tem por objetivo investigar as contribuições socioeconômicas advindas do processo de inclusão social de carroceiros e cidadãos desempregados por meio das práticas de gestão de resíduos da construção civil, implementadas pelo poder público da cidade de Belo Horizonte, MG. Para tanto, realizou-se uma pesquisa descritiva e sistematizou-se um quadro de referência que inclui algumas reflexões teóricas sobre gestão ambiental pública como instrumento de inclusão social. A análise dos resultados evidencia que essas práticas proporcionaram a inclusão social de carroceiros, possibilitando novas oportunidades de trabalho e geração de renda, resgatando a auto-estima e contribuindo para a conscientização ambiental desse grupo de trabalhadores. Além disso, constatou-se que a Ecobloco, uma fábrica de artefatos de concreto produzidos com matéria-prima proveniente de resíduos da construção civil reciclados, tem proporcionado a oportunidade de emprego e renda para cidadãos excluídos do mercado de trabalho.

Palavras-chave: gestão ambiental, inclusão social, resíduos da construção civil.

\section{Introdução}

Desde o final do século passado, a globalização, a introdução de novas tecnologias e a constante qualificação da mão-de-obra têm proporcionado a evolução do processo produtivo. Por outro lado, os cidadãos que não têm acesso a essas melhorias tornam-se marginalizados e excluídos da sociedade, sem acesso aos bens de consumo e serviços básicos, sem oportunidade de emprego formal, ficando subordinados ao subemprego ou ao emprego informal. Há, ainda, a frágil competência do Estado em oferecer políticas públicas destinadas à educação, saúde e geração de emprego e renda.

Entretanto, com a autonomia outorgada pela Constituição de 1988 aos municípios, diversas políticas públicas têm sido formuladas em âmbito local. Entre elas, encontram-se as políticas públicas ambientais, implementadas por meio de ações que visam proteger o meio ambiente, combater a poluição e gerar emprego e renda, proporcionando a inclusão social de parcelas da população local.
Entre as políticas públicas, destacam-se aquelas que visam à redução e ao aproveitamento de resíduos sólidos gerados pela indústria da construção civil. O atual modelo de produção da indústria da construção civil utiliza, quase sempre, recursos naturais não-renováveis e resíduos sempre são gerados. A geração de resíduos sólidos neste ramo da indústria ocorre por meio de diversos processos produtivos relacionados à execução de um empreendimento imobiliário, como modernização, manutenção e demolições de obras (John, 2000; John e Agopyan, 2000). Principalmente com o crescimento populacional e o aumento de pessoas em centros urbanos, esses resíduos transformam-se em graves problemas urbanos (Ângulo et al., 2001).

Uma entre as diferentes formas de amenizar os impactos dos resíduos da construção civil é a reciclagem desses materiais. Para John (2004), a reciclagem é uma oportunidade de transformação de uma fonte importante 
de despesa em uma fonte de faturamento. Dessa forma, os resíduos são considerados um importante insumo no processo produtivo e com valor econômico agregado (Demajorovic, 1996). Segundo esse autor, processos de coleta seletiva e reciclagem, promovidos por diversos governos locais, representantes do setor privado e por uma população de catadores, vêm se multiplicando nos países em desenvolvimento, sendo responsáveis por um sistema informal de coleta.

Na cidade de Belo Horizonte, aproximadamente 42\% dos resíduos coletados são de entulho oriundo da construção civil. Na tentativa de mitigar e reduzir os impactos ambientais desses resíduos, a prefeitura vem, desde os meados da década de 1990, formulando políticas públicas e implementando um conjunto de práticas de gestão ambiental na tentativa de reduzir os impactos ambientais da indústria da construção civil na cidade, bem como proporcionar a geração de emprego e renda e, conseqüentemente, a inclusão social de atores envolvidos nas práticas de gestão dos resíduos da construção civil.

Entre esses atores, destacam-se os carroceiros, que foram inseridos no programa de reciclagem de entulho da prefeitura de Belo Horizonte como agentes coletores de resíduos da construção civil e os cidadãos beneficiados com emprego e renda, proporcionados pela criação de uma fábrica de artefatos de concreto (Ecobloco), cuja matéria-prima é proveniente da reciclagem dos referidos resíduos.

Este trabalho investigou as contribuições socioeconômicas do processo de inclusão social adquiridas pelos carroceiros e integrantes da Ecobloco por meio das práticas de gestão de resíduos da construção civil, implementadas pelo poder público da cidade de Belo Horizonte, MG.

\section{Gestão ambiental pública como prática de inclusão social}

A nova Constituição atribuiu novas responsabilidades aos municípios referentes à promoção de programas e políticas públicas, visando à melhoria da qualidade de vida nas cidades, até então, centralizados no governo federal. Os municípios, juntamente com outras esferas governamentais, passaram a empreender ações visando "proteger o meio ambiente e combater a poluição em qualquer de suas formas" (BRASIL, 1988, art. 23, inciso VI) e a "controlar a produção, a comercialização e o emprego de técnicas, métodos e substâncias que comportem risco para a vida, a qualidade de vida e o meio ambiente" (BRASIL, 1988, art. 225, inciso V). (Silva, 1992, p.103).

A autonomia outorgada pela Carta Magna aos municípios estimulou a formulação de diversas políticas públicas em âmbito local. Em algumas cidades, como São Paulo, Belo Horizonte, Vitória, Porto Alegre, Curi- tiba, Santos e Rio de Janeiro, a administração municipal buscou introduzir, em suas ações, alguns princípios de desenvolvimento urbano sustentável. Em outros termos, esses municípios passaram a formular e a implementar, de forma democrática, políticas públicas que promovam a qualidade de vida dos seus habitantes, a ampliação da consciência dos problemas relacionados ao meio ambiente e a preservação dos recursos naturais. Trata-se da inclusão desses municípios à tendência da multissetorialização defendida pelo movimento ambientalista (Menezes, 1997).

A possibilidade de os municípios elaborarem suas próprias leis orgânicas facilitou a inserção do planejamento em sua realidade política e socioambiental. Com isso, vem ocorrendo, cada vez mais, um convencimento dos governantes de que a esfera local é o lugar mais apropriado para a prática de uma gestão ambiental mais efetiva e participativa, capaz de reverter o atual quadro caótico presente na maioria das grandes cidades brasileiras, mediante um novo modelo de desenvolvimento urbano política, econômica, social e ambientalmente sustentável (Menezes, 1997). É na cidade que se podem produzir conhecimentos e informação para melhorar a eficiência do uso de recursos naturais e para reduzir desperdícios, reciclar e aproveitar recursos, se auto-abastecendo dos bens materiais necessários (Ribeiro, 1992).

Segundo Silva (1992), proteger o meio ambiente, do ponto de vista municipal, pode significar ações, como: a escolha inteligente dos materiais e desenhos das redes e sistemas de serviços públicos; a penalização dos despejos poluentes de estabelecimentos industriais, a edição de leis claras, simples e abrangentes sobre poluição, uso e ocupação do solo urbano; a criação de espaços territoriais especialmente protegidos; e campanhas de coleta seletiva e reciclagem de lixo, além de mudança de práticas na administração pública, entre outras.

Além disso, a administração municipal deve estar atenta para a integração de cada um de seus órgãos administrativos, visando à construção de uma sintonia de propósitos, valores e princípios, bem como desenvolver instrumentos legais, na forma de planos diretores ambientalmente compatíveis e leis urbanísticas com forte conteúdo preservacionista.

No âmbito municipal, uma gestão ambiental integrada deve levar em consideração diversas dimensões (econômica, social, cultural e ambiental), incluindo o fortalecimento de cooperações intermunicipais e a participação da população na definição de prioridades associadas às práticas de gestão ambiental que devem envolver planejamento, controle, acompanhamento e comunicação permanentes (Nunesmaia, 2000). Essa mesma autora sugere que essas práticas de gestão devem considerar as seguintes linhas de ação: 
1) o desenvolvimento de linhas de tratamento (tecnologias limpas) de resíduos, priorizando a redução e a valorização; 2) a economia (viabilidade); 3) a comunicação/educação ambiental (o envolvimento dos diferentes atores sociais); 4) o social (a inclusão social, o emprego); e 5) o ambiental (os aspectos sanitários, os riscos, a saúde humana). A integração também concerne às categorias dos atores (ou agentes): produtores de resíduos, catadores, municípios e cooperação entre municípios, prestadores de serviços (terceirização), indústrias (indústrias de reciclagem).

Para Demajorovic (1994) e Jacobi (2002), essas linhas de ações devem ser articuladas com políticas sociais municipais. Assim, as práticas de gestão ambiental podem se tornar mecanismos de mediação da construção da cidadania, ampliação da conscientização política da população, geração de emprego e renda, desde que elas: a) envolvam a participação do setor público, privado, populações locais, entre outros atores; b) considere os aspectos socioculturais e o saber local; c) desenvolva o sentido de responsabilidade social e ambiental; e d) respeite os limites estabelecidos pela legislação vigente, que regula a questão ambiental no âmbito local, estadual e federal. Entretanto, como destaca Jacobi (2002), a viabilização de práticas de gestão ambiental que promovam a articulação entre a redução da degradação ambiental e a geração de renda poderá encontrar algumas dificuldades socioculturais. Em outros termos, nem sempre a intencionalidade e os objetivos concretos das práticas de gestão ambiental são compreendidos por diversos atores que nelas estão envolvidos. Para o referido autor, essas práticas requerem um período de amadurecimento para que os seus resultados sejam legitimados e reconhecidos pela sociedade.

Entre os resultados positivos dessas práticas de gestão ambiental destacam-se aqueles que promovem a inclusão social de camadas populacionais marginalizadas por meio da geração de empregos, aumento da consciência ambiental, ampliação e fortalecimento da co-responsabilidade da sociedade na fiscalização e controle dos agentes responsáveis pela degradação socioambiental, redução dos impactos ambientais derivados das atividades econômicas, no caso específico deste trabalho, as atividades da construção civil.

A gestão do meio ambiente urbano representa, então, um desafio complexo que, além de levar em consideração a preservação dos recursos naturais, deve também assegurar condições de vida digna à população, propiciando que parcelas da sociedade não sejam excluídas do processo de desenvolvimento das cidades (Silva, 2005). Políticas sociais, que visem à qualidade de vida dessas parcelas da sociedade, podem ser implantadas de maneira criativa e por meio de experiências inovadoras que envolvam a participação da população (Fleury et al., 1997). Além disso, as políticas sociais, por meio da implementação de projetos que gerem ações diretas e participativas entre governo e cidadão, viabilizam a inclusão social (Calderon, 2003).

Inclusão social que pode ser, segundo Borges (2004, p. 1):

[...] compreendida como uma atitude política diante das desigualdades e injustiças sociais, voltada para a instituição de espaços de comunicação, realização e participação na sociedade de pessoas, grupos e comunidades que, em função de circunstâncias históricas, são privados dos seus direitos e impedidos de se realizarem como cidadãos.

Uma forma de realizar a inclusão social de cidadãos pode estar presente nos princípios do associativismo e do cooperativismo (Soares-Baptista, 2003). Esse autor, citando Laville (1997), sugere que as associações resultarão possivelmente em novas formas de produção de identidade e normas sociais.

O associativismo, como forma de inclusão social, sugere a aproximação de governos e cidadãos. Segundo Calderon (2003):

[...] viabilizar a inclusão social é responsabilidade do poder público, e exigir do Estado a qualidade de gestão necessária para o desenvolvimento social, é responsabilidade do cidadão (p. 5). [...] As questões que permeiam as diretrizes da inclusão social e cidadania, são ancoradas em procedimentos técnicos, operativos e nas relações humanas, desprendendose dos conceitos teóricos e abstratos, transformando-se em índices, números, discussões, implementações, inovações, flexibilização e conhecimento. Conhecimento que penetra no cerne do individuo de forma natural e espontânea, estabelecendo raízes consistentes na mentalidade social (p. 12).

Entre as práticas de inclusão social implementadas pelo poder público local da cidade de Belo Horizonte por meio da gestão de resíduos da construção, destacam-se aquela destinada à inclusão de carroceiros como integrantes da rede receptora e recicladora desses resíduos e a que proporciona a geração de emprego e renda a cidadãos por meio da fabricação e venda de artefatos de concreto produzidos com resíduos da construção civil reciclados. Essas práticas, bem como suas contribuições socioeconômicas, serão abordadas na seção de análise dos resultados desta pesquisa.

\section{Procedimentos metodológicos}

Para a compreensão das práticas de gestão de resíduos da construção civil implementadas pelo poder público 
da cidade de Belo Horizonte e suas múltiplas dimensões, optou-se por realizar uma pesquisa de natureza qualitativa (Bogdan e Biklen, 1994; Laville e Dionne, 1999). Assim sendo, optou-se pelo método de pesquisa descritiva que permite a construção de um processo analítico que considera diferentes interpretações dos diversos atores sociais envolvidos com o fenômeno objeto da investigação (Bogdan e Biklen, 1994). Acredita-se que essa escolha metodológica produza explicações acerca das práticas de gestão de resíduos em questão, bem como sirva de referência para apreensão do contexto de inclusão social (Laville e Dionne, 1999) em que as referidas práticas estão inseridas, ou seja, o universo da pesquisa.

Neste trabalho considerou-se o município de Belo Horizonte como universo da pesquisa de campo, representado, para efeitos deste trabalho, pela Secretaria de Limpeza Urbana (SLU), incluindo sua sede, os locais apropriados para a coleta de resíduos da construção civil e as duas usinas de reciclagem de entulho. A cidade de Belo Horizonte foi escolhida para ser objeto de análise por implementar, de forma pioneira, há mais de dez anos, um conjunto de práticas de gestão dos resíduos oriundos das atividades da construção civil. A experiência recebeu vários prêmios e poderá ser reproduzida em outros municípios, individualmente ou na forma de consórcios, desde que respeitadas as especificidades locais, o estágio de desenvolvimento local, os aspectos socioculturais da população e a disponibilidade de recursos e os interesses públicos e privados associados às práticas de gestão ambiental.

Para garantir o rigor científico exigido pelo mundo acadêmico para qualquer atividade relacionada à pesquisa científica (Brito, 2000), optou-se por desenvolver um protocolo científico orientado pela lógica da triangulação, ou seja, pela aplicação combinada de diversas técnicas de coleta de dados, ao longo do período de junho 2004 a maio de 2005.

A triangulação de diversos procedimentos de coleta de dados foi dividida em quatro etapas. Na primeira fase da pesquisa, optou-se, após um contato inicial com os técnicos responsáveis pelo Programa de Correção das Deposições Clandestinas e Reciclagem de Entulho (também denominado Programa de Reciclagem de Entulho), da Prefeitura Municipal de Belo Horizonte, por realizar uma visita técnica que serviu de referência para a obtenção dos primeiros registros acerca da realidade pesquisada. Nessa oportunidade, foram visitadas a sede da Superintendência de Limpeza Urbana (SLU), a usina de reciclagem de entulho localizada no Bairro Estoril, duas unidades de recebimento de pequenos volumes (URPV) e obras da prefeitura em que se utilizavam os materiais reciclados pelas usinas. Na segunda etapa, foi realizada uma análise documental de acervos relativos à história da Superinten- dência de Limpeza Urbana (SLU), bem como elementos historiográficos a respeito da criação do Programa de Correção das Deposições Clandestinas e Reciclagem de Entulho. Nesse procedimento de pesquisa, buscou-se identificar as especificidades das políticas públicas e das práticas de gestão ambiental adotadas pelo governo municipal, desde a criação do referido programa.

Na terceira fase, após a preparação de um roteiro semiestruturado, foram realizadas 17 entrevistas que contaram com a participação de profissionais da SLU responsáveis pelo Programa de Correção das Deposições Clandestinas e Reciclagem de Entulho e com outros atores integrantes e participantes deste programa, como se segue: a) coordenador do programa; b) engenheiro integrante do departamento de projetos especiais; c) arquiteta da prefeitura integrante do departamento de projetos especiais; d) secretária-adjunta de serviços urbanos da prefeitura; e) ex-gerente da usina de reciclagem de entulho Estoril; f) ex-gerente da usina de reciclagem de entulho Pampulha; g) ex-diretor técnico do programa; h) ex-coordenador do programa; i) responsável pela frente social do Programa de Correção Ambiental e Reciclagem com Carroceiros; j) sete carroceiros que operam o sistema de coleta de resíduos; e k) representante da Ecobloco. $\mathrm{Na}$ escolha dos entrevistados, optou-se pelo critério do envolvimento e importância do informante no contexto da pesquisa de campo, bem como pelo critério de indicação de um informante pelo outro que fora entrevistado.

Optou-se pela escolha de entrevistas semi-estruturadas, por elas serem menos rígidas, no sentido de conservarem certa padronização das perguntas, sem imporem opções de respostas (Laville e Dionne, 1999), permitindo que o entrevistado manifeste suas opiniões, seus pontos de vista e seus argumentos (Alencar, 2000). Todas as entrevistas foram gravadas com a autorização prévia dos entrevistados e, para a reprodução, respeitou-se a linguagem por eles utilizada. Cabe ressaltar que os carroceiros foram entrevistados em quatro URPVs diferentes e, pelo fato de as entrevistas terem sido realizadas durante o horário de trabalho, a escolha foi aleatória, ou seja, foi entrevistado o carroceiro que estava presente no momento da visita do pesquisador. Além disso, sistematizou-se uma caderneta de campo, na qual eram anotadas as observações do pesquisador, bem como os relatos das pessoas sobre os fatos relacionados às práticas de gestão ambiental em questão (Bogdan e Biklen, 1994).

Finalmente, na quarta fase do processo de coleta de dados, retornou-se à sede da SLU para novas entrevistas com gestores e para o levantamento de dados que complementassem as lacunas de informações, solucionando, assim, as dúvidas identificadas nas fases anteriores. Esse retorno ocorreu após a sistematização e a análise crítica inicial dos dados levantados. Julga-se relevante mencio- 
nar que esse retorno ao campo foi determinante na melhoria da qualidade das informações que serão analisadas ao longo do próximo tópico.

Após a realização das fases já mencionadas e, fundamentada no quadro teórico sistematizado para este trabalho, que inclui um conjunto de reflexões teóricas acerca da gestão ambiental pública como instrumento de inclusão social, desenvolveu-se a análise dos resultados desta pesquisa. Esse procedimento analítico envolveu a organização e a sistematização das informações obtidas por meio das entrevistas, a exploração em profundidade das informações relevantes para a compreensão das práticas de gestão ambiental em questão e o tratamento e a interpretação dos resultados da pesquisa. Esse último processo incluiu uma análise das particularidades das práticas de gestão ambiental dos resíduos da construção civil implementadas pelo poder público municipal como alternativa de inclusão social.

\section{Práticas de gestão de resíduos da construção civil na cidade de Belo Horizonte: origem e rede de coleta}

Em 1993, a SLU contratou uma empresa de consultoria para avaliar as condições de deposição do entulho da construção civil na cidade, cujo trabalho revelou que: Belo Horizonte apresentava 134 pontos de deposição clandestina de entulho e uma geração média de $425 \mathrm{~m}^{3}$ de entulho e terra por dia, cuja remoção gerava uma despesa no orçamento da prefeitura de U\$ $1.070 .000,00$ por ano. O diagnóstico oferecido pela consultoria também demonstrou a necessidade de se implantar 4 estações de reciclagem e 12 unidades de recebimento de pequenos volumes (URPV) para suprir esse volume de resíduo gerado. Essa constatação levou a prefeitura a organizar e a implementar duas práticas de combate e prevenção: 1) a rede receptora do resíduo: composta pela implantação das URPVs, pela implantação das estações de reciclagem de entulho e pelos aterros municipais de inerte; e 2) a rede programática: composta por práticas de gestão específicas: educação e informação, recuperação de áreas degradadas e projeto de fiscalização.

As referidas práticas de combate e prevenção fazem parte do Programa de Correção das Deposições Clandestinas e Reciclagem de Entulho, que foi implantado com o objetivo de promover a correção dos problemas ambientais urbanos gerados pela deposição indiscriminada de resíduos de construção na malha urbana. Mais especificamente, com o programa objetiva-se: a) recuperar áreas degradadas pela deposição clandestina; b) minimizar a ocupação do aterro sanitário com entulho potencialmente reciclável; c) implantar uma rede descentralizada de locais para a deposição dos resíduos de construção; d) pro- duzir material reciclado de boa qualidade para utilização, prioritariamente, em obras públicas e de interesse social; e e) permitir a substituição daqueles materiais convencionalmente empregados na construção civil, preferencialmente em obras públicas e de interesse social.

A área identificada como a principal geradora de deposições clandestinas foi a região oeste de Belo Horizonte, e o bairro Estoril foi definido como o local mais apropriado para a implantação da primeira estação de reciclagem de entulho, a Estação de Reciclagem de Entulho Estoril. Juntamente com a implantação da primeira estação de reciclagem, em 1995, iniciou-se a implantação das primeiras URPVs. Com o funcionamento bem sucedido da primeira estação, a implantação da segunda, que já estava prevista, aconteceu em função da demanda da sociedade por esse serviço. Assim, em 1996, foi implantada a Estação de Reciclagem de Entulho Pampulha.

No caso do Programa de Correção das Deposições Clandestinas e Reciclagem de Entulho, pode-se observar que sua legitimação pela sociedade inicia-se com a implantação de uma segunda usina de reciclagem como demanda da sociedade. Como lembra Jacobi (2002), a intencionalidade de qualquer prática de gestão ambiental necessita de um período de amadurecimento para que se obtenha legitimidade por parte da sociedade.

A instalação das referidas estações de coleta e reciclagem deu origem ao processo de consolidação de uma rede receptora de resíduos da construção civil, que passou a integrar outros atores, como os carroceiros, considerados, até então, pelo poder público, como degradadores do meio ambiente. Esses atores foram incorporados à rede de coleta como prestadores de serviço de transporte de entulhos (oriundos de pequenas construções ou reformas), evitando, assim, o depósito desse material em locais impróprios. Sendo assim, a partir de 1997, a prefeitura passou a incorporar o carroceiro no programa de reciclagem de entulho. Como resultado dessas práticas, a rede receptora de resíduos, criada pelo poder público, passou a articular os seguintes atores e elementos: a) pequeno gerador de entulho: nessa categoria encontramse os agentes geradores de resíduos de pequenas reformas, construções e outros processos que não excedam o volume de $2 \mathrm{~m}^{3} / \mathrm{dia}$; b) grande gerador de entulho: esses agentes são responsáveis pela geração de entulho de qualquer natureza que exceda o volume de $2 \mathrm{~m}^{3} / \mathrm{dia}$; c) carroceiro: trata-se do cidadão comum que faz uso de carroça de tração animal para a coleta e o transporte de entulho ou materiais da construção civil; d) unidades de recebimento de pequenos volumes (URPV): têm por finalidade receber gratuitamente pequenos volumes (até $2 \mathrm{~m}^{3} /$ dia por gerador) de resíduos de construção (madeira, terra, telhas, tijolo, concreto, metais, gesso, etc.) podas, pneus, outros objetos volumosos (móveis, eletrodo- 
mésticos, etc.). Além das caçambas para recebimento dos materiais citados, possui uma área construída que abriga um escritório de controle gerenciado por um funcionário da prefeitura, banheiro, local para refeições dos carroceiros, bebedouro para os animais, tronco para vacinação e marcação dos animais e contêineres para coleta seletiva (papel, metal, plástico e vidro); e e) estações de reciclagem de entulho: estão instaladas em áreas públicas totalmente fechadas de, no mínimo $6.000 \mathrm{~m}^{2}$ e têm por finalidade receber e reciclar resíduos da construção civil.

A interação entre esses agentes produz três opções de coleta de resíduos, a saber: a) opção 1: após a geração do entulho, o pequeno gerador liga para o "disque carroça", telefone da prefeitura destinado exclusivamente para a contratação do serviço de transporte de entulho por meio de carroceiros. O carroceiro recolhe o material (entulho, podas, móveis velhos, etc.) e o transporta para a URPV, onde é feita a separação do material de acordo com sua natureza em caçambas próprias. À medida que as caçambas de entulho estão completas, o caminhão da prefeitura as recolhe, levando-as para as estações de reciclagem; b) opção 2: o próprio cidadão pode transportar o material ou entulho do local de geração para a URPV, desde que não exceda $2 \mathrm{~m} 3 /$ dia; e c) opção 3: o grande gerador de entulho destina o entulho gerado, acima de $2 \mathrm{~m}^{3}$, diretamente para as estações de reciclagem.

Paralelamente à implementação da infra-estrutura da rede de coleta de resíduos, discutida neste tópico, o poder público municipal formulou e implementou um conjunto de políticas e práticas de comunicação, mobilização social, recuperação de áreas degradadas e de fiscalização ambiental. As referidas práticas são denominadas, pelo poder público, de rede programática, cujo propósito tem sido dinamizar a rede receptora do resíduo. Para tanto, elas apresentam as seguintes particularidades: a) a comunicação e a mobilização social: essa prática tem um caráter educativo, sensibilizatório e organizativo, que visa ao envolvimento e à efetiva participação do cidadão na busca de soluções para os problemas decorrentes da geração dos resíduos sólidos; b) recuperação de áreas degradadas: essa prática consiste em promover a limpeza dos locais públicos que, geralmente, são usados para deposições clandestinas. Esses espaços seguem um projeto paisagístico, que conta com cercamento do local, pintura do meio-fio e jardinagem; e c) monitoramento e fiscalização: consiste em atuar com os agentes transportadores de resíduos e com a população em geral, na coibição do lançamento indiscriminado de resíduos.

Atualmente, além das duas estações de reciclagem em pleno funcionamento, o número atual é de 23 URPVs espalhadas pelo município. Os carroceiros, por sua vez, foram organizados em associações de acordo com a área da cidade onde eles atuam, sendo três associações já conso- lidadas. Esse associativismo e a participação nas práticas de gestão de resíduos da construção civil têm proporcionado aos carroceiros diversos benefícios sociais e econômicos que serão discutidos no próximo tópico.

\section{As contribuicões socioeconômicas da inclusão social geradas pelas práticas de gestão de resíduos da construção civil}

\subsection{A gestão de resíduos como prática de inclusão social de carroceiros}

O processo de inclusão dos carroceiros na rede de coleta de resíduos nasceu de um problema provocado pelos carroceiros que eram os grandes vilões da deposição clandestina de resíduos da construção civil. Esse diagnóstico pautou-se no relatório da consultoria realizada em 1993, na cidade de Belo Horizonte e foi descrita no tópico anterior. Nesse diagnóstico, constatou-se que aquele trabalhador que usava sua carroça de tração animal para transportar os resíduos, depositava-os em lotes vagos, córregos e outros lugares públicos inadequados. Dessa forma, em 1997, deu-se início ao processo de inserção dos carroceiros à rede receptora de resíduos com o Programa de Correção Ambiental e Reciclagem com Carroceiros. Segundo o Coordenador do programa de reciclagem de entulho:

Dificilmente a prefeitura teria condições de combatê-los [os carroceiros] apenas no modo do comando e controle; esses dois comandos 'você não faz isso senão eu te multo', não funcionam. Então, a partir do momento que nós procuramos incorporá-los ao nosso programa, nós fizemos uma rede de recepção na cidade desses pequenos volumes.

Essa prática teve o objetivo de promover a inclusão social dos carroceiros na gestão integrada de resíduos adotada no município de Belo Horizonte. Esse processo possibilitou novas oportunidades de trabalho e contribuiu para a conscientização ambiental do referido grupo de trabalhadores que, até então, eram marginalizados pelo poder público e pela sociedade local (Jacobi, 2002).

Foram diversas as ações utilizadas para este fim. Na realidade, buscou-se ampliar a aproximação entre os carroceiros e o poder público municipal, orientada pelos princípios do respeito mútuo, da cooperação e do compartilhamento de informações e de conhecimento. Essas ações se desenvolvem pela integração de três frentes de trabalho organizadas e gerenciadas pela PMBH, que são:

a) Frente técnica: tem o objetivo de informar os carroceiros sobre a importância ambiental do programa e as conseqüências das deposições clandestinas em córregos, lotes vagos e outros locais inadequados, incluindo os benefícios da deposição de entulho de forma ambientalmen- 
te correta e a participação deles como agente de limpeza urbana. Além disso, o poder público fornece aos carroceiros um local apropriado, ou seja, ambientalmente correto, para a deposição de entulho, que são as 23 URPVs localizadas em diversos locais do espaço territorial da cidade, e para o serviço de transporte por eles prestado.

A frente técnica também tem sido responsável pela gestão do cadastro dos carroceiros da cidade de Belo Horizonte. Esse processo conta com a participação da Empresa de Transportes e Trânsito de Belo Horizonte, a BHTRANS como parceira. A SLU realiza o cadastro e a BHTRANS realiza o emplacamento, o licenciamento e a legalização das carroças por meio do Decreto 10.293, de 2 de Julho de 2000. Esse decreto regula, ainda, a condição de autorização prévia do condutor para a condução da carroça. Assim sendo, são expedidos certificados de registro e licenciamento da carroça e uma carteira de condutor de veículo de tração animal.

Inicialmente, os carroceiros não acreditavam muito nesse trabalho, pois desconfiavam de que o cadastramento serviria de instrumento de coerção e ampliação do controle, além de facilitar a aplicação de multas por parte do poder público. Segundo Jacobi (2002), essa desconfiança deriva da lenta legitimidade das práticas de gestão ambiental que requerem, por sua vez, um período de amadurecimento para que as pessoas nelas se envolvam.

Encontra-se em fase de estudo a instalação de um biogestor que produzirá energia com o uso das fezes dos animais dos carroceiros, que seriam coletadas por meio de um "fraudão", instalado nas carroças. Planeja-se produzir um botijão de gás de $13 \mathrm{~kg}$ com as fezes coletadas diariamente de cada cinco animais. Após a sua produção, o botijão de gás será fornecido ao carroceiro a um preço mais acessível.

b) Frente social: tem o objetivo de resgatar a identidade do carroceiro como trabalhador e como cidadão, por meio da inclusão social. Pelos levantamentos socioeconômicos realizados por essa frente de trabalho, verificase que a grande maioria da amostra de 1.384 carroceiros possui baixo nível de escolaridade, ou seja, 14,6\% são analfabetos; $14,6 \%$ estudaram até a segunda série do ensino fundamental; $22,80 \%$ até a $4^{\mathrm{a}}$ série do ensino fundamental; $34,8 \%$ cursaram da $5^{\text {a a }} 8^{\text {a }}$ série do ensino fundamental; $8,4 \%$ cursam ou cursaram o ensino médio; e $4,8 \%$ não responderam (Figura 1a).

Pela análise do perfil sociodemográfico desses parceiros do poder público (Figura 1b), verifica-se também que $31,8 \%$ trabalhavam anteriormente na indústria da construção civil; $8,6 \%$ são oriundos da atividade de serviços gerais; 7,6\% trabalhavam com vigilância; $8,0 \%$, em atividades industriais; $9,1 \%$ têm a profissão de carroceiro como primeira ocupação; e 34,9\% são oriundos de outras ocupações.
A frente social também tem sido responsável pela mobilização dos carroceiros, motivando-os a ingressar e participar das associações. Atualmente, existem três associações de carroceiros consolidadas, que lutam pelos interesses da classe, aproximando governo e cidadãos e proporcionando novas formas de produção de identidade dos carroceiros e normas sociais (Soares-Baptista, 2003). Esse trabalho conjunto entre o poder público e as associações tornou possível o reconhecimento da profissão de carroceiro pelo Ministério do Trabalho, em Belo Horizonte. Outro resultado da mobilização provocada pela frente social foi a criação do dia municipal do carroceiro de Belo Horizonte. Esse dia tem sido comemorado, anualmente, no primeiro domingo do mês de setembro, envolvendo manifestações como "carroceata" nas proximidades da lagoa da Pampulha, bênção dos animais por um padre e entrega de diploma para os carroceiros que fizeram o maior número de viagens de entulho para as URPVs.

Nas ações da frente social, inclui-se ainda um encontro anual para a realização de palestras, em que são abordados temas de caráter social, técnico e veterinário, tais como: controle da verminose; medicina do trabalho; problemas digestivos do eqüino; inseminação artificial; e como alimentar adequadamente o cavalo de tração, entre outros assuntos. Outros cursos também já foram ministrados, tais como: manejo de eqüinos para carroceiros; curso básico para tratador de cavalo; e seminários de educação para o trânsito. Algumas regionais da prefeitura também

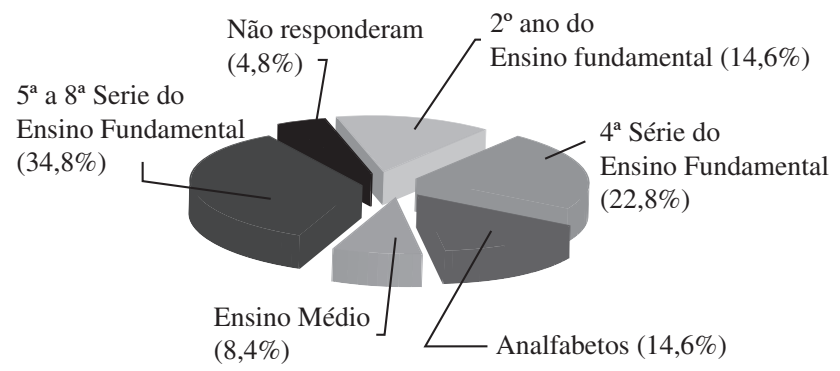

(a)

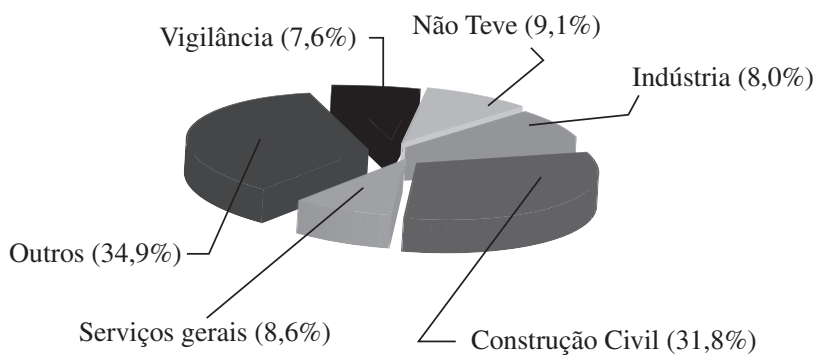

(b)

Figura 1. a) Nível de escolaridade dos carroceiros; e b) Atividades anteriores dos carroceiros. Fonte: Adaptado de Rezende et al., (2004). 
oferecem curso de alfabetização e está em fase de estudos a implantação de um programa de saúde bucal, que tem sido uma reivindicação dos próprios carroceiros.

c) Frente veterinária: tem como objetivo cuidar da saúde do animal utilizado pelos carroceiros. Para tanto, o poder público, em parceria com a escola de veterinária da UFMG, oferece atendimento médico-hospitalar contínuo, bem como orientação sobre nutrição e saúde animal. Todos os animais dos carroceiros são marcados e registrados pelo poder público. Esse convênio também tem sido responsável pelo trabalho de inseminação artificial e melhoramento genético dos animais. A frente veterinária, em parceria com o serviço de zoonoses da Secretaria Municipal de Saúde, também promove a vacinação anual dos animais e registra todas as informações sobre o processo de vacinação, para um melhor controle da saúde e nutrição do animal. Está em fase de estudos a implantação de sistemas de pastoreio e abrigo coletivo para os animais, de modo a lhes garantir boa alimentação e bem-estar.

A análise dos seguintes relatos colhidos com os carroceiros entrevistados e pelos dados analisados neste tópico permite constatar que a atuação da frente veterinária tem sido significativa para a saúde do animal, proporcionando o bem-estar do animal e a satisfação do proprietário.

Essa vacinação foi uma coisa que veio facilitar muito a nossa vida e fortalecer o animal. Porque a gente sabe, o animal sadio, a gente sabe o animal que tem problema. E dessa forma o animal tá sendo menos maltratado também (carroceiro 3).

O trabalho contínuo dessas três frentes (técnica, social e veterinária) tem gerado ações diretas e participativas entre poder público municipal e cidadão, viabilizando a inclusão social (Calderon, 2003). Além disso, tem proporcionado ao carroceiro o resgate de sua auto-estima, preservado a sua identidade como trabalhador e, principalmente, tem lhe permitido o exercício da cidadania. Com a implantação das políticas e práticas de gestão de resíduos da construção civil, a atuação desses cidadãos passou a ser legitimada pela sociedade local e o trabalho dos carroceiros passou a ser reconhecido como algo relevante para o combate à degradação ambiental.

[...] antes do projeto eles [os carroceiros] eram vistos como os sujões da cidade, como aquela pessoa que, quando você queria desfazer, esconder um resíduo, você contratava um carroceiro. Hoje, eles são agentes ambientais. Lógico que a gente não consegue atingir todos, mas, hoje, a população os vê como um prestador de serviço. Assim como nós temos o serviço de táxi, transporte escolar, o carroceiro também é reconhecido. A partir do momento que você identifica, você faz emplacamentos, você dá uma licença para ele transitar, eles se sentem pessoas importantes na cidade, ele sai da clandestinidade e entra na formalidade [...] isso melhora a auto-estima dele (ex-gerente de serviços gerais e reciclagem/Pampulha).

Essa percepção também está presente nos relatos dos próprios carroceiros que têm resgatado, com esse programa, o orgulho da profissão e a auto-estima por serem reconhecidos como cidadãos e pelo serviço que prestam à sociedade.

Faz 42 anos que eu trabalho de carroceiro. Melhorou demais da conta.. Eles dão vacina, marca os animais, dá ração por mês, todas as condições pra gente trabalhar. Eu tenho treze filhos, trato tudo tirando da carroça [...]. (carroceiro 2).

$\mathrm{Eu}$ acho bom esse projeto. Melhorou muito, assim, pelo menos a moral da gente, porque, de primeiro, carroceiro é carroceiro, mas, hoje, não, o carroceiro, hoje, ele é um trabalhador reconhecido em vários lugares, reconhecido pela população. Porque, de primeiro, o carroceiro podia ser um ladrão, uma coisa qualquer, hoje não (carroceiro 5).

As práticas de inclusão social também proporcionam ao carroceiro e a sua família a possibilidade de lazer, convívio social, além de expectativas quanto ao futuro dessas famílias. Trata-se de uma prática com a qual se ampliam as possibilidades de vivenciar a cidadania.

[...] todo ano a gente tem uma carroceata, a gente pode levar as crianças, é muito carroceiro que vai. E, de vez em quando, tem uma festa na UFMG. A gente pode levar a família, tem almoço, tem tudo. Os carroceiros de BH tudo reúne lá. Quem pode ir, leva a família. Então melhorou bem. Até pra família da gente melhorou, porque, a respeito de área de lazer, porque a gente leva a família pra festa, as crianças ficam tudo satisfeita (carroceiro 5).

Dentro dos cursos que a gente tava dando, curso de ferradura, de pneu, o carroceiro ficou encantado e pediu pra filha fazer. E, no final, veio me dizer: "olha acho que a minha filha vai fazer veterinária" (assessora técnica da SLU coordenadora do projeto com carroceiros).

A análise desses relatos reforça a tese de Junqueira (1998). Para esse autor, somente uma política não basta para resolver problemas sociais, pois eles requerem a ação integrada das diversas políticas públicas que articulam saberes e experiências que produzem efeito sinérgico em situações de desenvolvimento e inclusão social. No contexto estudado, com a ação integrada das três frentes 
de trabalho, produziu-se um efeito sinérgico da inclusão social dos carroceiros.

O aumento da renda dos carroceiros também pode ser visto como forma de inclusão social. Atualmente, a renda varia de acordo com a regional em que ele trabalha, geralmente, em função da maior ou da menor geração de resíduos da localidade. Em média, a maior parte dos carroceiros, ou seja, $49 \%$, fatura entre $\mathrm{R} \$ 50,00$ e $\mathrm{R} \$ 100,00$ por semana (Figura 2); $13 \%$ faturam de $\mathrm{R} \$ 100,00$ a R $\$ 200,00$ por semana; $27 \%$ faturam até $\mathrm{R} \$ 50,00$ semanais; apenas $2 \%$ conseguem faturar acima de $\mathrm{R} \$ 200,00$ por semana; $7 \%$ não souberam responder; e $2 \%$ não informaram. A renda da maioria dos carroceiros provém da cobrança do frete, que segue a lei da oferta e da procura. Assim, quem define e controla os preços do frete são os próprios carroceiros. Essa liberdade de mercado tem provocado algumas distorções na cotação do frete, que chega a variar de $\mathrm{R} \$ 7,00$ a $\mathrm{R} \$ 40,00$ para o mesmo serviço. Ressalta-se que alguns carroceiros complementam suas rendas prestando serviços de transporte de materiais de construção entre as lojas e o pequeno construtor.

\subsection{Produção de artefatos de concreto: uma alternativa para a inclusão social}

Outra forma de inclusão social implementada pela prefeitura de Belo Horizonte, por meio de políticas e práticas de gestão dos resíduos da construção civil, foi a implementação da fábrica de produção de artefatos de concreto em que são utilizados agregados reciclados como matéria-prima. Essa fábrica foi denominada, por seus idealizadores, de Ecobloco. Trata-se de um projeto de inclusão social de pessoas que tinham uma trajetória de rua, ou seja, pessoas que migraram, por um motivo qualquer, para a cidade de Belo Horizonte e não exerceram a sua cidadania na plenitude, dada a sua exclusão do mercado de trabalho.

O projeto Ecobloco surgiu de um trabalho escolar realizado por três alunos do Sebrae. Esse trabalho focava a utilização de material da construção civil reciclado por uma empresa para fabricação de artefatos de concreto. O poder público municipal decidiu apoiar a idéia e, posteriormente, o Ministério do Desenvolvimento Social e Combate à Fome cedeu os recursos para financiar a sua implementação como recorda o seu gestor:

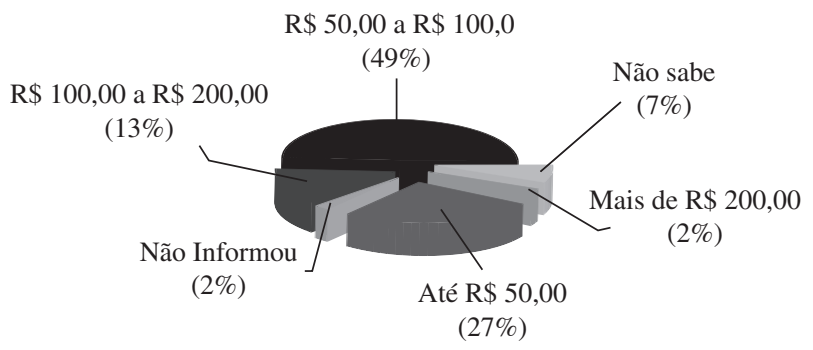

Figura 2. Renda semanal dos carroceiros. Fonte: SLU.
Ecobloco é um projeto que pega três pontos importantes, três itens importantíssimos na nossa vida, que é inclusão social, reciclagem e empreendedorismo. Inclusão social porque a gente tá buscando aquelas pessoas que estão excluídas do mercado de trabalho, da cidadania. A reciclagem porque a gente tá reaproveitando, a gente tá dando um destino nobre pra um material nobre que era jogado no lixo. E empreendedorismo porque nós estamos colocando essas pessoas pra criar um negócio. São pessoas que estão vindo aqui, além da inclusão social, elas estão aprendendo a gerenciar um negócio, elas estão aprendendo a ser autosuficientes (representante da Ecobloco).

Com a implantação da Ecobloco, um grupo de dez pessoas foi capacitado para o trabalho com o acompanhamento de técnicos e da assistência social. O projeto tem sido gerenciado por um profissional com experiência acadêmica, cuja função é treinar as pessoas selecionadas e coordenar a produção e a comercialização dos artefatos de concreto produzidos pela Ecobloco, que foi inaugurada em junho de 2004 e encontra-se instalada na Estação de Reciclagem Estoril.

Atualmente, a fábrica trabalha com a confecção de blocos de concreto, considerados o carro-chefe da produção, para atender à demanda crescente de mercado. Entretanto, há a intenção de se fabricarem outros artefatos de concreto. A matéria-prima empregada é proveniente da reciclagem do material coletado pela rede receptora. Os blocos fabricados são vendidos para as casas de material de construção localizadas no entorno da Estação de Reciclagem Estoril e revendidas. A qualidade desses artefatos fabricados é garantida por parcerias com uma empresa especializada que tem apoiado o projeto Ecobloco e com a Escola de Engenharia da UFMG, que iniciou os trabalhos de ensaios desse material e realiza, atualmente, pesquisas para a melhoria da qualidade dos blocos fabricados.

A produção e a comercialização desses blocos de concreto é a principal fonte de recursos que sustenta o referido projeto. Além dessa sustentação financeira, o lucro advindo da comercialização dos artefatos é dividido entre os dez participantes do projeto que não mantêm contratos formais de trabalho com a Ecobloco. Trata-se de uma empresa de participação que visa à inclusão social:

Porque o programa maior que a gente tem com essa questão de inclusão social com essas pessoas de baixa renda, que estão fora do mercado, é que, se nós simplesmente ajudarmos essas pessoas com uma cesta básica, com dinheiro, com um lugar pra morar, isso aí não é o bastante. Eu acho que se você dá um trabalho e condições dessa pessoa ser independente, ou 
seja, essa pessoa conseguir tocar um negócio pra frente, conseguir se manter no mercado de trabalho, nós estamos simplesmente tirando essa pessoa dessa situação de não-cidadão, desse nível inferior da sociedade (representante da Ecobloco).

A despeito da sua contribuição socioeconômica, o projeto Ecobloco tem encontrado algumas restrições que vão desde a operação com equipamentos de baixa produtividade, passando pelas dificuldades de acesso ao mercado devido à concorrência, até rejeição por parte de clientes em potencial que desconhecem a qualidade dos produtos fabricados com o agregado reciclado.

Esse projeto, além de permitir a inclusão social desses integrantes, gera emprego e renda e contribui para a redução dos impactos ambientais por meio da substituição de recursos não-renováveis, por agregados reciclados. Porém, faltam ainda a divulgação da qualidade dos blocos de concreto produzidos pela Ecobloco e a conscientização da população local quanto ao uso de produtos ambientalmente compatíveis.

Além disso, a continuidade das práticas de inclusão social, discutidas anteriormente, depende da articulação de novas formas de interação, do desenvolvimento de ações educativas ambientais que ampliem o nível de conscientização da população e da adoção de novas tecnologias de gestão sustentáveis de resíduos da construção civil. Entretanto, pelas análises dos resultados deste trabalho, verifica-se que a rede de políticas e práticas de gestão de resíduos da construção civil implementadas pelo poder público da cidade de Belo Horizonte produziu efeitos sinérgicos significativos para o meio ambiente.

\section{Considerações finais}

Os resultados desta pesquisa evidenciam que a implantação de uma rede de política pública de gestão dos resíduos da construção civil exigiu a implantação de uma infra-estrutura e a instalação de equipamentos em diferentes pontos estratégicos. Associado a esta infra-estrutura, o poder público local formulou e implementou, levando-se em consideração o saber e a cultura urbana local, um conjunto de práticas de gestão, educação ambiental e mobilização social, que foram determinantes na mudança de comportamento da população em geral e de atores envolvidos no processo de gestão dos resíduos da construção civil, tais como os carroceiros e os integrantes da Ecobloco.

A natureza social das práticas de gestão de resíduos da construção civil permitiu que novas oportunidades de trabalho e renda fossem geradas para os carroceiros e integrantes da empresa de participação social Ecobloco. Com essas práticas, promoveu-se o resgate da auto-estima desses cidadãos, ampliando a sua consciência ambiental e melhorando a sua qualidade de vida.
A implantação do Programa de Correção Ambiental e Reciclagem com Carroceiros proporcionou a inclusão social dos carroceiros e novas oportunidades de trabalho, contribuindo para a conscientização ambiental por parte desse grupo de trabalhadores, que passaram de pessoas marginalizadas a cidadãos e profissionais reconhecidos pelo poder público e pela sociedade local. Mais especificamente, a integração de três frentes de trabalho (técnica, social e veterinária) organizadas e gerenciadas pela $\mathrm{PMBH}$, por meio do referido programa, proporcionou aos carroceiros: maior aproximação e compartilhamento de informações com o poder público municipal; participação do carroceiro como agente de limpeza urbana e executor de deposição de entulho ambientalmente correta; resgate da identidade do profissional carroceiro com o reconhecimento da profissão pelo Ministério do Trabalho em Belo Horizonte; exercício de sua cidadania; incentivo e apoio ao associativismo; criação de um dia municipal comemorativo dedicado ao carroceiro; melhor convívio social com seus familiares e seus pares; acesso a encontros e palestras de caráter técnico, social e veterinário; atendimento médico-hospitalar; e acompanhamento veterinário para os animais utilizados no transporte de resíduos da construção, melhoramento genético e vacinação dos animais. A análise dos relatos coletados durante a pesquisa de campo revelou, ainda, que o trabalho das três frentes tem sido reconhecido pelos próprios carroceiros, melhorando sua auto-estima e resgatando o orgulho de ser carroceiro. Em síntese, a ação integrada das três frentes de trabalho produziu um efeito sinérgico da inclusão social dos carroceiros.

A análise dos resultados demonstrou, ainda, que o projeto Ecobloco tem proporcionado a oportunidade de emprego e renda para cidadãos excluídos do mercado de trabalho, por meio da implementação da fábrica de produção de artefatos de concreto em que são utilizados agregados reciclados como matéria-prima. Esta fábrica, além de contribuir ambientalmente com o aproveitamento de resíduos da construção em substituição a recursos naturais não-renováveis, promove o aprendizado a seus integrantes, desperta princípios básicos do empreendedorismo, bem como gera renda a cada um deles com a venda dos artefatos. Entretanto, apesar de toda a contribuição socioeconômica e ambiental do referido projeto, constatou-se que é necessário uma maior divulgação da qualidade dos artefatos produzidos pela Ecobloco, maior conscientização da população e, principalmente, investimentos da iniciativa privada. Esses fatores, quando forem incorporados de forma intensa e constante ao projeto Ecobloco, poderão promover a adoção de novas tecnologias e, ainda, aumentar o potencial de fabricação e venda desses artefatos, aumentando, conseqüentemente, o número de cidadãos beneficiados. 
ALENCAR, E. Métodos de pesquisa nas organizações. Lavras: UFLA/FAEPE, 2000. 109 p.

ÂNGUlO, S. C.; ZORDAN, S. E.; JOHN, V. M. Desenvolvimento sustentável e a reciclagem de resíduos na construção civil. Disponível em: <http://www.reciclagem.pcc.usp.br/ftp/artigo\%20IV_CT206_2001.pdf> Acesso: 24 jan. 2005.

BOGDAN, R. C.; BIKLEN, S. K. Investigação qualitativa em educação. Porto: Porto Editora, 1994. 335 p.

BORGES, C. A. M. Rede e inclusão social. Anais do $2^{\circ}$ Congresso Brasileiro de Extensão Universitária. Belo Horizonte, 2004. Disponível em: <http://www.ufmg.br/congrext/Direitos/Direitos62.pdf> Acesso em: 13 fev. 2006.

BRASIL. Constituição (1988). Constituição da República Federativa do Brasil, 1988. Brasília: Senado Federal, Centro Gráfico, 1988. 292 p.

CALDERON, H. Inclusão social. In: VIII Congreso Internacional del CLAD sobre la Reforma del Estado y de la Administración Pública, Panamá, 28-31 Oct. 2003. Disponível em: <http://unpan1.un.org/intradoc/groups/ public/documents/CLAD/clad0047349.pdf > Acesso: 13 fev. 2006

DEMAJOROVIC, J. Meio ambiente e resíduos sólidos. Dissertação (Mestrado) - Fundação Getúlio Vargas, São Paulo, 1994.

A evolução dos modelos de gestão de resíduos sólidos e seus instrumentos. Cadernos Fundap, São Paulo, n. 20, p. 47-58, mai./ago. 1996.

FLEURY, S.; CARVALHO de, A. I.; MANOTAS, N.; BLOCH, R. NEVARES, S. Municipalização da saúde e poder local no Brasil. In: XXI ENCONTRO DA ASSOCIAÇÃO NACIONAL DE PÓS-GRADUAÇÃO E PESQUISA EM ADMINISTRAÇÃO, 1997, Rio das Pedras. Anais... CD-ROOM.

JACOBI, P. Meio ambiente urbano e sustentabilidade: alguns elementos para a reflexão. In: CAVALCANTI, C. (org.). Meio ambiente, desenvolvimento sustentável e políticas públicas. São Paulo: Cortez; Recife: Fundação Joaquim Nabuco, 4. ed. p. 384-390, 2002.

JOHN, V. M.; AGOPYAN, V. Reciclagem de resíduos da construção. In: SEMINÁRIO RECICLAGEM DE RESÍDUOS SÓLIDOS DOMÉSTICOS, 2000, São Paulo. Disponível em <http://www.recycle.pcc.usp.br/artigos1. htm>. Acesso em 27 jan. 2005.
JOHN, V. M. Reciclagem de resíduos na construção civil: contribuição para uma metodologia de pesquisa e desenvolvimento. 2000. 113 f. Tese (Livre docência) - Escola Politécnica da Universidade de São Paulo.

Desenvolvimento sustentável, construção civil, reciclagem e trabalho multidisciplinar. Disponível em: <http://www.reciclagem.pcc.usp.br/des_sustentavel. htm>. Acesso em: 5 set. 2004.

JUNQUEIRA, R. G. P. A intersetorialidade do ponto de vista da educação ambiental: um estudo de caso. Revista de Administração Pública, Rio de Janeiro, v. 32, n. 2, p. 79-91, mar./abr. 1998.

LAVILlE, C.; DIONNE, J. A construção do saber. Belo Horizonte: UFMG, 1999. 279 p.

MENEZES, C. L. Emergência e evolução da política ambiental urbana no Brasil: do estado novo à nova república. Revista de Administração Pública, Rio de Janeiro, v. 31, n. 1, p. 70-95, jan./fev. 1997.

NUNESMAIA, M. F. A gestão de resíduos urbanos e suas limitações. Revista Baiana de Tecnologia, Salvador, v. 17, n. 1, p. 1120-129, jan./abr. 2000.

REZENDE, H. H. C.; PALHARES, M. S.; AGUIAR, E. G.; SILVA, R. H. A.; PEREIRA, M. S. N. Impacto da migração dos carroceiros de Belo Horizonte: setor formal para o setor informal. In: Encontro de Extensão da Universidade Federal de Minas Gerais, Belo Horizonte, 2004. Disponível em: <http://www.ufmg.br/proex/arquivos/ 7Encontro/Meio2.pdf> Acesso em: 28 jun. 2005.

RIBEIRO, M. A. A crise ambiental urbana brasileira. Revista de Administração Pública, Rio de Janeiro, v. 26, n. 4, p. 52-80, out./dez. 1992.

SILVA, J. A. O. da. O município e a proteção ambiental. Revista de Administração Pública, Rio de Janeiro, v. 26, n. 3, p. 88-106, jul./set. 1992.

SILVA da, S. T. Políticas públicas e estratégias de sustentabilidade urbana. Disponível em: <http://www.esmpu. gov.br/publicacoes/meioambiente/pdf/Solange_Teles_ Politicas_publicas_e_sustentabilidade.pdf > Acesso em: 26 mai. 2005.

SOARES-BAPTISTA, R. D. G. Reciclagem, Ação Social e Política de Gerenciamento do Lixo em São Paulo. In: XXVII ENCONTRO DA ASSOCIAÇÃO NACIONAL DE PÓS-GRADUAÇÃO E PESQUISA EM ADMINISTRAÇÃO, 2003, Atibaia. Anais... CD-ROOM. 


\title{
WASTE MANAGEMENT IN CIVIL CONSTRUCTION AS A PRACTICE OF SOCIAL INCLUSION IN THE CITY OF BELO HORIZONTE - MG
}

\begin{abstract}
The aim of this article is to investigate the social and economical contributions which took place in the process of social inclusion of cart-drivers and unemployed citizens by means of waste management practice in civil construction implemented by the public authorities of the city of Belo Horizonte - MG. Taking this into account, descriptive research was carried out and references that include some theoretical reflections on public management as an instrument of social inclusion were added. The analysis of the results shows that these practices provided the social inclusion of cart-drivers, making new opportunities of work possible and generating more income, building up their self esteem and contributing to the awareness of this related group of workers. Moreover, there is evidence that the Ecobloco, a plant which manufactures produced concrete devices of raw material from recycled waste of civil construction, has provided job opportunities and income for excluded citizens of the job market.
\end{abstract}

Keywords: environmental management, social inclusion, civil construction waste. 